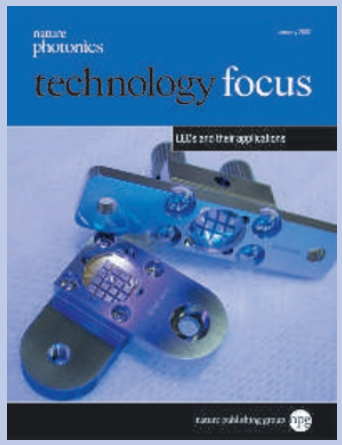

Cover image

Prototype high-power UV LEDs from the Japanese firm Nichia. Interview p38

EDITOR: OLIVER GRAYDON

ASSOCIATE EDITORS: AMBER JENKINS, DAVID GEVAUX, RACHEL PEI CHIN WON

PRODUCTION EDITORS: SIMON GERRARD, CHRIS GILLOCH

COPY EDITOR: ANNA DEMMING

ART EDITOR: KAREN MOORE

\title{
Haitz's law
}

W

elcome to the Nature Photonics

Technology Focus on LEDs. This is the

first in a series of regular supplements devoted to important photonic technologies that are changing the world around us by enabling new applications or transforming existing ones.

Each Technology Focus will consist of a series of articles describing market trends, research results, emerging applications, as well as the latest business news and product releases in the relevant field.

The LED seems an ideal topic to start with. Over the past forty years this compound semiconductor-based light source has evolved to become a bright, efficient source of white, red, green and blue light that is giving cars, interior lighting and signage a radical new look.

In fact, progress in LED performance has been so rapid that it has been described by a logarithmic law, akin to Moore's law for microelectronics. Although everyone with a passing interest in science seems to have heard of Moore's law (which states that the number of transistors in an integrated circuit doubles every two years), far fewer seem to be aware of 'Haitz's law'.

Named after Roland Haitz, a now-retired scientist from Agilent Technologies, the law forecasts that every 10 years the amount of light generated by an LED increases by a factor of 20, while the cost per lumen (unit of useful light emitted) falls by a factor of 10 . What is astonishing is that not only have these forecasts been fulfilled but over the past five years there are signs that they have actually been over achieved.

Today's state-of-the-art white LEDs are now fast approaching the efficacy of fluorescent lamps (around 60-90 $\mathrm{lm} \mathrm{W}^{-1}$ ) and it is predicted that they will break the $100 \mathrm{~lm} \mathrm{~W}^{-1}$ figure within the next two years, p33. In addition, their brightness is now sufficiently high that a small cluster can act as the daylight running lamp on cars and the next target is the entire headlamp itself. In fact, if the opinions of the authors of the article on p31 are to be believed, within the next five to ten years, filament bulbs will disappear from cars altogether. Enjoy reading and please keep an eye out for our next Technology Focus in our March issue on the topic of optical communications.
MARKET ANALYSIS

25 The story of a new light source

Robert V. Steele

\section{RESEARCH HIGHLIGHTS}

29 Purer white light and the latest advances in LED technology

\section{INDUSTRY PERSPECTIVE}

31

Automotive: Car makers embrace LED signals Steve Landau and Jeff Erion

33 Lighting:

White phosphorescent LEDs offer efficient answer Brian D'Andrade

\section{BUSINESS NEWS Epistar expansion and other commercial developments}

\section{PRODUCT HIGHLIGHTS 37 Infrared imaging devices, deep-UV LEDs and more}

\section{INTERVIEW}

38

The future of ultraviolet LEDs Adarsh Sandhu 